Review Article

\title{
Is the human species still evolving? To where?
}

\author{
Francisco M. Salzano \\ Departamento de Genética, Instituto de Biociências, Universidade Federal do Rio Grande do Sul, \\ Porto Alegre, RS, Brazil.
}

\begin{abstract}
The questions of the title have been considered in several ways. First, indications of the traits which make us humans were considered. Then the behavior and culture concepts were examined, and the biology and culture interactions discussed, with an emphasis on the similarities and differences between the genetic and cultural transmissions. Next diverse types of selective pressures were reviewed, and finally pessimistic and optimistic views of our future contrasted. Vigorous action against acts which lead to exclusion and discriminatory policies against human subjects is needed.
\end{abstract}

Keywords: biology and culture, genetic selection, cultural selection, fluctuating selection, exploratory behavior.

\section{What Makes us Humans?}

We are the product of a process that started 3.8 billion years ago, with the origin of life, being just one of the astonishing different forms which emerged with the evolutionary process. But how different are we from the other living beings? What makes us humans? We differ from the other primates by a series of characteristics, and a list of selected anatomical and physiological traits is given in Table 1. It is impossible to single out any one of them as the most important, since the evolutionary factors act over the organism as a whole. But we are the only vertebrate species with a bipedal gait and erect posture; birds are bipedal, but their backbone is generally horizontal, and the kangaroo bipedalism does not involve erect posture. Bonobos and some ancestral Homo species are or were only partially biped. Without doubt one of the most important human characteristic is our brain, that is three times larger than that of the chimpanzee and much more complex, with the cerebral cortex proportionally much larger than those of other apes. Other important morphological traits involved a modification of the vocal tract, which made possible the origin of language in a much more sophisticated form than the rudiments found in other species; opposable and larger thumbs (important for tool manipulation), and a series of characteristics related to reproduction and life history that were related to the evolution of social life.

Other selected typical human traits are listed in Table 2. The type of social organization evolved in our species

Send correspondence to Francisco M. Salzano. Departamento de Genética, Instituto de Biociências, Universidade Federal do Rio Grande do Sul, Caixa Postal 15053, 91501-970 Porto Alegre, RS, Brazil. E-mail: francisco.salzano@ufrgs.br. was of fundamental importance for its survival and evolutionary history; and a distinctive process, made possible by a series of traits related to cognition, was culture, whose complexity is many orders of magnitude higher than related phenomena found in other organisms.

\section{The Behavior and Culture Concepts}

Human behavior can be defined as the set of attitudes and reactions of an individual or group in response to a stimulus. Multiple factors influence behavior, which could be classified in three categories: genetic, ontogenetic and cultural. Genes supply the material bases for hormones and other proteins which would be primarily responsible for the individual norm of reaction. But the life history of each person is also important, at all stages of her/his life, involving the physical and sociocultural environments. The relationships among these variables are non-linear, being influenced by intergenerational construction/deconstruction factors, as well as feedback processes. Our biological constitution favors wide flexibility rather than fixed, immutable, patterns of behavior responses (Fuentes, 2009).

It is generally held that a fundamental distinction of our species in relation to all other animals is the complexity of our culture. But the term is of difficult definition, and some colleagues even maintain that there are as many culture concepts as there are anthropologists! Laland et al. (2010) define it as "information that is capable of affecting individuals' behavior, which they acquire from other individuals through teaching, imitation, and other forms of social learning". From this perspective it can be said that the spreading of this ability can be to a certain extent independent of the environment. Foley and Lahr (2011) adopt this 
Table 1 - Selected anatomical and physiological differences between humans and other primates.

1. Erect posture. Skull balanced upright. S-shaped spine

2. Larger, more complex, and asymmetric brains

3. Face remodeling. Reduction of the size of jaws and teeth. Presence of a chin

4. Modification of the vocal track and larynx

5. Reduction of body hair. Changes in the skin glands

6. Permanently enlarged breasts in adult females

7. Cryptic ovulation

8. Opposable and larger thumbs

9. High longevity

Source: Klein and Takahata (2002); Varki et al. (2008); Ayala (2010).

Table 2 - Selected typical Homo sapiens characteristics.

\section{Social organization}

Life in societies structured in nuclear families, highly dependent offspring, the grandmother factor.

\section{Cognition and culture}

Symbolic language, abstraction capacity, self-consciousness and deathconsciousness, theory of mind, tool construction and their intergenerational transfer, political institutions, legal codes, science, art, ethics, religion.

Source: Varki et al. (2008); Ayala (2010).

same concept, but proposed that the different types of culture were and are the outcome of the way in which kinbased human communities reproduce over generations, fissioning; and that the rate of this fissioning is strongly influenced by ecological and geographical factors.

\section{Biology and Culture}

The dialectic relationships between biology and culture followed an interesting evolution. In the $19^{\text {th }}$ and beginning of the $20^{\text {th }}$ centuries there was a consensus that genetic factors influenced in a marked way the capacity of acquiring and developing culture. Afterwards, by the influence, for instance, of Franz Boas (1858-1942), an opposing change happened, and all sociocultural patterns were supposed to be completely free of biological influence. In recent years a reaction to these Manichean views occurred, with emphasis on interpretive approaches postulating an interaction between these two sets of elements. For instance, Laland et al. (2010) list and characterize ten mathematical models of gene-culture co-evolution.

\section{Genetic and Cultural Transmissions}

A comparison, between the genetic and cultural transmissions is provided in Table 3 . Only relatively recently models were developed at the cultural side to interpret and quantify phenomena of this type, but now it is possible to compare in a more specific way these two types of processes. The main difference between the two processes is that the rate of change is much faster in cultural as compared to genetic evolution. This is because the genetic transmission most often occurs in a vertical (parentoffspring) way, while the cultural one can also happen vertically, but in addition can be transmitted horizontally (between persons of the same generation) or obliquely (teacher-pupil). Methods to identify how the transmission occurred in specific ways were presented by Borgerhoff Mulder et al. (2006).

A special type of transmission is that related to the intergenerational inheritance of material goods, a problem that is indirectly related to the unequal wealth and class formation in human societies. This question has been extensively considered in a set of contributions (one introduction, five articles, and the answers of their authors to 10 comments) published in Current Anthropology, Volume 51 (Bowles et al., 2010; whole material, p. 7-126).

Hewlett et al. (2002) considered genetic, geographical, cultural in general and linguistic traits, with the objective of understanding Africa's cultural variability. Three

Table 3 - Comparison between the genetic and cultural transmission.

\begin{tabular}{lll}
\hline Characteristic & \multicolumn{2}{c}{ Transmission } \\
\cline { 2 - 3 } & Genetic & Cultural \\
\hline 1. Unit of replication & Gene & Meme $^{1}$, seme $^{1}$ \\
2. Information vector & DNA & Behavior, central nervous system \\
3. Transmission mechanism & DNA duplication & Imitation, social facilitation, learning, teaching \\
4. Variation & Mutations and other types of DNA lesion & Learning errors, innovations \\
5. Impact of the variation & Mostly deleterious & Variable \\
6. Transmission of acquired traits & No & Yes \\
7. Type of process & Darwinian & Darwinian or Lamarckian \\
8. Rate of change & Slow & Fast \\
\hline
\end{tabular}

${ }^{1}$ Meme would be a unit associated with imitation, while seme derives from signal and emphasizes the symbolic nature of culture (Hewlett et al., 2002). Source: Danchin et al. (2004), with modifications. 
models were examined: (a) cultural diffusion; (b) local adaptations; and (c) demic diffusion. Individual seme analyses indicated different associations in relation to the models, but those related to kinship proved to be quite conserved, and their distribution to follow mainly the demic diffusion model.

\section{Positive Genetic Selection and Cultural Selection}

Recently methods have been developed to detect statistical signatures in the human genome of recent, strong positive selection, namely, genes that have been favored by natural selection over the past 100 thousand years. Such signals include high-frequency alleles in linkage disequilibrium, unusually long haplotypes of low diversity, and an excess of rare variants.

As a result of these efforts about two thousand genes had been identified as having such selective sweeps, and many of their distributions could have been influenced by cultural factors. A list referring to 126 of them is given in Table 4 . They are related to diet, immunity, climate adaptation, visible characteristics, and cognition. Some of these factors are interwoven; for instance, the variability in skin color genes could be related both to climate adaptation (exposure to ultraviolet radiation) and sexual selection (assortative mating).

\section{Fluctuating Selection}

The identification of selective factors may in some cases be difficult due to the fact that these pressures may vary in direction and intensity along time. Two examples from research performed by our group may illustrate this point.

The enhancer of gene expression HACNS1, with a 546-base pair sequence, is highly conserved in all terrestrial vertebrate genomes. However, there was an accumulation of 16 human specific changes since the human-chimpanzee split, which occurred six million years ago. Alternative explanations for this rupture of the conservation would be (a) positive selection; or (b) biased gene conversion, and the discussions held concerning these two possibilities had not at the time considered population data.

We (Hünemeier et al., 2010) studied 83 South Amerindians, 11 Eskimos, 35 Europeans, 37 Bantu and nonBantu Sub-Saharan speakers, and 28 Brazilian admixed subjects and found no variation in this DNA region. Similar lack of variability was found in four Africans, five Europeans or Euro-derived persons, two Asians, one Paleo-Eskim$\mathrm{o}$, and one Neandertal sequences, whose whole genomes were publicly available. No difference was found. These results favor the interpretation of past positive and present conservative selection, as would be expected in a region which influences Homo-specific traits as important as opposable thumbs, manual dexterity, and bipedal walking.

Another locus which showed peculiarities in terms of selection is Paired box gene 9 (PAX9). Its coding sequence is composed of four exons, in a total of 2.1 thousand base pairs. The first acts uniquely as the start codon. Exon 2 is responsible for sequence-specific contacts with DNA, and, together with exon 4 , shows an impressive absence of nucleotide sequence variation among 44 mammal species. In contrast, exon 3 shows a different picture. We (PaixãoCôrtes et al., 2011) recently sequenced its 138 base pairs (bp) and its 5' and 3' flanking regions (with $232 \mathrm{bp}$ and 220 bp respectively) in 138 Amerindians, 44 Eskimos, 14 Japanese, 15 Europeans, and 47 Africans. Nine mutations were scored in the coding sequence and six in its flanking regions; four of them are new South Amerindian singletons. Exon 3 nucleotide diversity is several orders of magnitude higher than its intronic regions.

An interesting polymorphism (Ala 240 Pro) occurs in this exon 3 . The derived allele $C$ (Pro) occurs everywhere in the world, with frequencies of $20 \%$ in Africans, $30 \%$ in Europeans, and $45 \%$ in Asians (Chinese and Japanese). In South Amerindians there is considerable variation among the 15 tribes tested, from zero to $40 \%$ (Paixão-Côrtes et al., 2011).

$P A X 9$ variability is therefore another example of fluctuating selection. The extreme conservation of four of its

Table 4 - Genes identified as subjected to fast positive selection and inferred cultural selection.

\begin{tabular}{lll}
\hline Genes & Function or phenotype & Inferred cultural selection \\
\hline At least 22 & Lactose digestion, food and alcohol metabolism & Cattle development, alcohol consumption \\
P450 Cytochrome & Detoxification of plant secondary products & Plant domestication \\
At least 31 & Immunity & Influence of the demographic density and exposure to \\
& new pathogens \\
At least 16 & Energy metabolism, tolerance to cold or heat & Exposure to new climates \\
At least 21 & Visible phenotype, skin color & Local adaptations, sexual selection \\
At least 29 & Nervous system, language & Social intelligence, complex cognition \\
$B M P 3, B M P R 2, B M P 5, G D F 5$ & Skeletal development & Dispersal and sexual selection \\
$M Y H 16, E N A M$ & Jaw muscle fibers, tooth-enamel thickness & Food cooking, diet
\end{tabular}

Source: Laland et al. (2010). 
exons point to purifying selection, but its exon 3 variability opens an evolutionary window for positive selection. Specifically the Ala 240 Pro polymorphism seems to be associated with third molar agenesis, especially so in Africa. A reduced number of molars may be evolutionarily advantageous; with the dramatic lifestyle and diet changes which occurred with the discovery of fire and the development of cooking devices, mastigatory strength became less important for survival, and dental arches have been reduced over hominid evolution. As a consequence third molars became frequently impacted or malpositioned, leading to periodontal diseases (caries, cysts, tumors). Any genetic change that would lead to their absence would be favored, and this seems to be the case for the $C$ (Pro) mutation (Pereira et al., 2006).

\section{Exploratory Behavior and DRD4}

The dopamine receptor $\mathrm{D} 4(D R D 4)$ gene is one of the most variable ones in the human genome and has an expressed variable number of tandem repeats (VNTR) of 48 base pairs. The number of repeats can vary from 2 to 11 . The $7 R$ allele was associated with behavior variables such as novelty-seeking, impulsivity and hyperactivity.

A recent investigation by our group (Tovo-Rodrigues et al., 2010) about the distribution of these alleles in South Amerindians (18 populations, 568 persons) displayed higher $7 R$ frequencies in populations with a recent past of hunter-gathering (average: $58 \%$ ) as compared to agriculturalists (48\%). Exploratory behaviors would be adaptive in nomad societies, because they allowed for more successful exploitation of resources. Conversely, in agriculturalist sedentary societies, novelty-seeking and exploratory behaviors would have social costs, because these populations developed intensive methods for land use in a given settled environment, which favor permanence.

We are confronted, therefore, with another example in which biological factors would influence a behavioral trait. Of course, the decision to migrate and explore new environments depends on many other factors, which should also be considered in an interdisciplinary context.

\section{The Future}

By now it should be clear that the answer to the first part of the title's question is affirmative. We are changing, and the evolutionary factors involved are heavily influenced by the respective cultural and socioeconomic environments, which provide a unique set of opportunities. What needs to be answered is to where we are heading to.

Table 5 presents two contrasting views about our future. There is no doubt that if the present economic and political model will persist, there is a real probability that the pessimistic view will prevail. The easiest way for the oppressed of escaping oppressors is the search for mystical or mythical beliefs ("my present life is worthless, but I will be
Table 5 - Two contrasting views about mankind's future.

1. The pessimistic view

1.1. Accentuation of the present gap which separates rich and poor individuals or nations.

1.2. Increase of violence between individuals and groups.

1.3. A world dominated by technology with monotonous repetition of the same patterns of culture and environment. Extinction of all wild species.

1.4. Triumph of mystical and mythical beliefs in social life.

\section{The optimistic view}

2.1. Health for all, individualized protection against diseases and food intoxication, appropriate science education, end of mystical and mythical beliefs.

2.2. Population control, scientifically established areas of conservation and management of endangered species, sophisticated techniques of environmental monitoring and appropriate pollution control.

2.3. Control of violence through scientific and political-economic measures.

2.4. Adequate wealth distribution - the maximum of happiness for the largest number of people.

Source: Salzano (2003), with modifications.

rewarded in God's Kingdom"). This behavior, coupled with resentment and lack of understanding of science's potential role for the improvement of life conditions, can lead to a nebulous world, in which extreme misery will necessarily coexist with scandalous wealth.

Against this tendency a consistent effort for the equalization of opportunities between individuals and nations should be made. Science has contributed to a substantial betterment of the world's life conditions (examples: increase in life expectancy, better food quantity and quality, protection against environmental stresses, higher interaction between individuals and groups, prevention and cure of many diseases). But to reach the conditions indicated by the optimistic view science this is not enough. A vigorous political action in favor of the presently excluded and discriminated is equally necessary.

\section{Acknowledgments}

My research is financed by Conselho Nacional de Desenvolvimento Científico e Tecnológico (CNPq) and Fundação de Amparo à Pesquisa do Estado do Rio Grande do Sul (FAPERGS, Programa de Apoio a Núcleos de Excelência, PRONEX). Thanks are due to Charbel N. El-Hani (Universidade Federal da Bahia) for many helpful suggestions in a previous version of this manuscript.

\section{References}

Ayala F (2010) The difference of being human: Morality. Proc Natl Acad Sci USA 107(Suppl 2):9015-9022.

Borgerhoff Mulder M, Nunn CL and Towner MC (2006) Cultural macroevolution and the transmission of traits. Evol Anthropol 15:52-64. 
Bowles S, Smith EA and Borgerhoff Mulder M (2010) The emergence and persistence of inequality in premodern societies. Curr Anthropol 51:7-17.

Danchin E, Giraldeau L-A, Valone TJ and Wagner RH (2004) Public information: From nosy neighbors to cultural evolution. Science 305:487-491.

Foley RA and Lahr MM (2011) The evolution of the diversity of cultures. Phil Trans R Soc B 366:1080-1089.

Fuentes A (2009) A new synthesis. Resituating approaches to the evolution of human behavior. Anthropol Today 25:12-17.

Hewlett BS, Silvestri A and Guglielmino R (2002) Semes and genes in Africa. Curr Anthropol 43:313-321.

Hünemeier T, Ruiz-Linares A, Silveira A, Paixão-Côrtes VR, Salzano FM and Bortolini MC (2010) Population data support the adaptive nature of HACNS1 Sapiens/NeandertalChimpanzee differences in a limb expression domain. Am J Phys Anthropol 143:478-481.

Klein J and Takahata N (2002) Where Do We Come From? The Molecular Evidence for Human Descent. Springer, Berlin, $462 \mathrm{pp}$.

Laland KN, Odling-Smee J and Myles S (2010) How culture shaped the human genome: Bringing genetics and the human sciences together. Nat Rev Genet 11:137-148.

Pereira TV, Salzano FM, Mostowska A, Trzeciak WA, RuizLinares A, Chies JAB, Saavedra C, Nagamachi C, Hurtado
AM, Hill K, et al. (2006) Natural selection and molecular evolution in primate $P A X 9$ gene, a major determinant of tooth development. Proc Natl Acad Sci USA 103:56765681.

Paixão-Côrtes VR, Meyer D, Pereira TV, Mazières S, Elion J, Krishnamoorty R, Zago MA, Silva WA Jr, Salzano FM and Bortolini MC (2011) Genetic variation among major geographic groups supports a peculiar evolutionary trend in PAX9. PLoS One 6:e15656.

Salzano FM (2003) A patrimony to be preserved. Proc Intern Bioethics Comm UNESCO Ninth Session 2:95-102.

Tovo-Rodrigues L, Callegari-Jacques SM, Petzl-Erler ML, Tsuneto L, Salzano FM and Hutz MH (2010) Dopamine receptor D4 allele distribution in Amerindians: A reflection of past behavior differences? Am J Phys Anthropol 143:458464.

Varki A, Geschwind DH and Eichler EE (2008) Explaining human uniqueness: Genome interactions with environment, behavior and culture. Nat Rev Genet 9:749-763.

License information: This is an open-access article distributed under the terms of the Creative Commons Attribution License, which permits unrestricted use, distribution, and reproduction in any medium, provided the original work is properly cited. 